28. Schmidt-Sommerfeld, E Penn D, Wolf H 1983 Carnitine deficiency in premature infants receiving total parenteral nutrition: effect of L-carnitine supplementation. J Pediatr 102:931-935

29. Dancis J, Jansen V, Levitz M 1976 Transfer across perfused human placenta IV. Effect of protein binding on free fatty acids. Pediatr Res 10:5-10

30. Faber JJ, Thornburg KL 1981 The forces that drive inert solutes and water across the epitheliochorial placentae of the sheep and the goat and the hemochorial placentae of the rabbit and the guinea pig. In: Young $\mathbf{M}$ (ed). Placental Transfer: Methods and Interpretations. Placenta Suppl. 2, pp 203-213

31. Rebouche CJ 1977 Carnitine movement across muscle cell membranes. Studies in isolated rat muscle. Biophys Acta 471:145-155

32. Vary TC, Neely JR 1982 Characterization of carnitine transport in isolated perfused adult rat hearts. Am J Physiol 242:H585-H592

33. Christiansen RZ, Bremer J 1976 Active transport of butyrobetaine and carni- tine into isolated liver cells. Biochim Biophys Acta 448:562-577

34. Huth PJ, Shug AL 1980 Properties of carnitine transport in rat kidney cortex slices. Biochim Biophys Acta 602:621-634

35. Yoshioka T, Roux JF 1972 In vitro metabolism of palmitic acid in human fetal tissue. Pediatr Res 6:675-81

36. Swierczński J, Scisowski A, Aleksandrowicz Z 1976 Oxidation of palmitoylcarnitine by mitochondria isolated from human term placenta. Biochem Med 16:55-58

37. Beaconsfield P Ginsburg J 1979 Carbohydrate, fat and protein metabolism in the placenta: A clinician's review. In: Beaconsfield P, Villee C (eds) Placenta-A Neglected Experimental Animal. Pergamon Press, Oxford, pp 34 125

38. Bieber LL, Emaus R, Valkner K, Farrell S 1982 Possible functions of shortchain and medium-chain carnitine acyltransferases. Fed Proc 41:2858-2862

\title{
Aminophylline Reduces Hypoxic Ventilatory Depression: Possible Role of Adenosine
}

\author{
ROBERT A. DARNALL, JR. \\ Department of Pediatrics, University of Virginia Medical Center, Charlottesville, Virginia 22908
}

\begin{abstract}
Newborn infants and animals typically exhibit a paradoxical ventilatory response to hypoxia. The depressive phase of the response has not been adequately explained. It has been suggested that hypoxia may cause the release of inhibitory neuromodulators which depress ventilation. We have postulated that the nucleoside, adenosine, may be involved because 1 ) it is rapidly released during hypoxia, 2) it depresses ventilation, and 3) theophylline, a competitive inhibitor, has successfully been used to treat apnea of prematurity. Herein we describe the effects of aminophylline on ventilation during hypoxia in the spontaneously breathing newborn piglet administered both rapidly after ventilatory depression has occurred (bolus) and before the onset of hypoxia (pretreatment). Ten percent oxygen breathing produced a typical biphasic ventilatory response. The decrease in minute ventilation was caused by a decrease in both tidal volume and respiratory frequency. The bolus administration of aminophylline reversed the depression in minute ventilation $(p<$ $0.001)$ by increasing tital volume $(p<0.002)$. Pretreatment with aminophylline decreased the amount of ventilatory depression $(p<0.05)$ by preventing a decrease in respiratory frequency. We conclude that aminophylline, an adenosine antagonist, reduces the decrease in ventilation which occurs during hypoxia in the newborn. We speculate that adenosine may play a role in hypoxic ventilatory depression and respiratory control in the newborn. (Pediatr Res 19: 706-710, 1985)
\end{abstract}

\section{Abbreviations}

Ve, minute ventilation

f, respiratory frequency

Received April 16, 1984; accepted March 7, 1985.

Correspondence Dr. Robert A. Darnall, Jr., Department of Pediatrics, Box 386, University of Virginia Medical Center, Charlottesville, VA 22908.

Supported by Biomedical Research Support Award S07-RR05431-20 and by a grant from the American Lung Association.

\author{
Vt, tital volume \\ HR, heart rate \\ BPs, systolic blood pressure
}

The paradoxical ventilatory response to hypoxia has been well documented in the newborn animal and human, and may contribute to the etiology of neonatal apnea. The neonate typically exhibits a biphasic ventilatory response to hypoxia (1-3) characterized by a brief increase in Ve, followed by a sustained decrease which is further accentuated by the resumption of normoxic or hyperoxic gas inhalation. The initial increase in ventilation has conventionally been explained as reflecting peripheral chemoreceptor stimulation. The subsequent decrease, however, has not been satisfactorily explained. A failure of peripheral chemoreceptors is probably not involved (4-6) but a number of other mechanisms have been suggested including alterations in pulmonary mechanics (7), and hypoxic depression of central respiratory centers (8).

Central depression of respiration might be caused by a decrease in metabolic rate (9), alterations in cerebral blood flow (10), rapid exhaustion of facilitory neurotransmitter stores $(11-13)$, or the release of rapid acting inhibitory neuromodulator such as endogenous opioids (14) or GABA (15). We have recently postulated that the nucleoside, adenosine, may also be a candidate as an inhibitory neuromodulator $(16,17)$. Our postulate is based on three lines of evidence: 1) theophylline, a specific competitive inhibitor of adenosine, is effective in treating neonatal apnea $(18) ; 2)$ adenosine is rapidly released in the brain during hypoxia (19); and 3) adenosine depresses ventilation when administered systemically or applied to the brainstem (20). Herein we describe the effects of theophylline on the hypoxic ventilatory response both when administered prior to the onset of hypoxia (pretreatment) and when given rapidly during hypoxia (bolus). 


\section{MATERIALS AND METHODS}

The hypoxic newborn piglet was chosen as an experimental model because recent investigations have determined that the piglet exhibits a biphasic hypoxic ventilatory response similar to the human infant (10). A total of 25 newborn piglets less than three days of age and weighing $1082.2 \pm 302.4 \mathrm{~g}$ (mean \pm SD) were obtained from local farms on the day of study. All animals were lightly anesthetized with intramuscualr ketamine $(15 \mathrm{mg} /$ $\mathrm{kg}$ ) and xylazine $(1.5 \mathrm{mg} / \mathrm{kg})$ and intubated with a 2.5 to $3.5 \mathrm{~mm}$ cuffed endotracheal tube. The endotracheal tube was attached to a breathing circuit which provided a continuous supply of heated, humidified gas. A system using solenoid valves was designed to allow a rapid change from room air to a predetermined gas mixture without interrupting or changing flow. Expiratory flow was measured with a pneumotachygraph (Fleisch no. 0000) placed between the endotracheal tube and the breathing circuit and connected to a differential pressure transducer (Validyne MP-45-18-87) and was electronically integrated to volume.

A catheter as placed in the femoral artery, infused with normal saline at $3 \mathrm{ml} / \mathrm{h}$, and connected to a transducer (Stathem P23DB) for continuous blood pressure measurements. The ECG and HR were monitored using standard extremity electrodes and skin temperature was automatically adjusted under a servo-controlled radiant heat source to maintain core temperature between 38 and $39^{\circ} \mathrm{C}$., the normal body temperature for neonatal piglets. Arterial blood gases were analyzed using a clinical blood gas system (IL-113). Measurements of $f$, inspiratory and expiratory flow, expired volume, ECG, heart rate, and blood pressure were continuously displayed on a strip chart recorder (Beckman Dynagraph). From these data, mean Ve, f, Vt, HR, and BPs were calculated for each minute of study.

During each experiment, anesthesia was maintained by intramuscular injections of ketamine $(7.5 \mathrm{mg} / \mathrm{kg})$ and xylazine $(0.75$ $\mathrm{mg} / \mathrm{kg}$ ) given every 20 to 30 minutes. In a separate group of five piglets maintained in room air for $3 \mathrm{~h}$, this method did not affect $\mathrm{Ve}, \mathrm{f}, \mathrm{Vt}$, or respiratory pattern.

The effect or pretreatment with theophylline on the hypoxic ventilatory response was studied in 11 piglets. Each animal was used as its own control and a control hypoxic trial was followed by a treatment trial. The control trial consisted of rapidly decreasing the inspired oxygen concentration to 0.10 and maintaining this concentration for $6 \mathrm{~min}$. Normoxia was then resumed and maintained for another $5 \mathrm{~min}$. Theophylline in the form of aminophylline $(15 \mathrm{mg} / \mathrm{kg})$ was then administered intraarterially over $10 \mathrm{~min}$, and after $30 \mathrm{~min}$, the hypoxic trial was repeated. We determined in a separate group of five piglets, that aminophylline, at a dose of $15 \mathrm{mg} / \mathrm{kg}$, administered over $10 \mathrm{~min}$, resulted in theophylline levels of 12 to $15 \mu \mathrm{g} / \mathrm{ml} 30 \mathrm{~min}$ after the completion of the injection. Arterial blood gases were obtained from the femoral artery before and during the 6th $\mathrm{min}$ of hypoxia. The percentage change in Ve, $\mathrm{f}$, and $\mathrm{Vt}$ at 2 and $6 \mathrm{~min}$ and the absolute changes in arterial blood gas values, HR, and BPs at $6 \mathrm{~min}$ after the onset of hypoxia were compared for the control and pretreatment trials using paired $t$ tests corrected for the effect of multiple tests according to the method of Bonferroni (21).

The effects of a bolus injection of aminophylline administered during hypoxia was evaluated in 14 additional animals as part of another study. In all 14 animals, hypoxia was first induced by rapidly decreasing the inspired oxygen concentration to 0.10 . After $6 \mathrm{~min}$ of hypoxia, 7 animals received a bolus of $1.6 \mathrm{ml}$ of aminophylline mixed in normal saline $(15 \mathrm{mg} / \mathrm{kg})$ and seven animals recieved $1.6 \mathrm{ml}$ of a normal saline placebo, intraarterially over $1 \mathrm{~min}$. The animals were then observed for an additional 5 min before resuming normoxia. In another group of four animals, a bolus of aminophylline at a dose of $15 \mathrm{mg} / \mathrm{kg}$, administered over $1 \mathrm{~min}$ resulted in theophylline levels of 17 to $28 \mu \mathrm{g} /$ $\mathrm{ml}$. Arterial blood gases were obtained before and during the 6 th min of hypoxia, and then $5 \mathrm{~min}$ after either the saline or the aminophylline injection. The 6th min of hypoxia was used as a baseline and the percent changes in Ve, f, VT, and the absolute changes in arterial blood gases, HR, and BPs were compared for the two groups $5 \mathrm{~min}$ after the bolus injection of either aminophylline or saline. Unpaired $t$ tests were used to compare the means of each parameter.

The effect of theophylline on periodic breathing and respiratory irregularity was evaluated in both the pretreatment and bolus experiments. Periodicity was defined as alternating periods of breathing and apnea occuring at least twice sequentially during any 1-min period [adapted from Rigatto and Brady (2)]. Irregularity was defined as significant variation in both amplitude and frequency. In the pretreatment experiments, the 6th min of hypoxia of both the control and treatment trials was scored as either periodic or nonperiodic and either regular or irregular. In the bolus experiments, the 5th min after the aminophylline or saline bolus was similarly scored. The entire minute was scored for each variable according to the dominant pattern. The effect of hypoxia and aminophylline on the relative amount of periodic and irregular breathing was statistically evaluated using Fischer exact tests.

\section{RESULTS}

During hypoxia, breathing became irregular and some animals exhibited pronounced periodicity. Table 1 illustrates the effect of aminophylline on respiratory pattern. Both bolus $(p<0.05)$ and pretreatment $(p<0.005)$ with aminophylline appeared to prevent hypoxic respiratory irregularity with little effect on periodicity.

In the pretreatment experiments, hypoxia produced a typical biphasic response in the control trials, with a transient increase and then a sustained decrease in Ve, accompanied by corresponding changes in both $\mathrm{f}$ and $\mathrm{Vt}$. Following the control hypoxic trial, the administration of $15 \mathrm{mg} / \mathrm{kg}$ of aminophylline was associated with a transient increase in Ve accompanied by an increase in both $\mathrm{f}$ and $\mathrm{Vt}$. After $30 \mathrm{~min}, \mathrm{Vt}$ was significantly greater than baseline $(7.4 \pm 1.5$ versus $6.2 \pm 1.3 \mathrm{ml} / \mathrm{kg} ; p<0.05)$. After pretreatment with aminophylline, hypoxia also caused an initial increase in Ve with accompanying increases in both $\mathrm{f}$ and $\mathrm{Vt}$. These changes were not different from those observed in the control trials. The decrease in Ve, however, was reduced after treatment with aminophylline. The percentage changes in $\mathrm{Ve}, \mathrm{f}$, and $\mathrm{Vt}$ during the control and aminophylline pretreatment hypoxic trials are compared in Figure 1.

The difference between the decreases in Ve in the control and the aminophylline pretreatment trials was due to a difference in the changes in $\mathrm{f}$. While there were no differences in the decreases in $\mathrm{Vt}, \mathrm{f}$ decreased in the control hypoxia trials and remained elevated in the aminophylline trials. By the 6 th min of hypoxia, f was $6.5 \pm 8.3 \%$ below baseline in the control group compared to $11.0 \pm 10.8 \%$ above baseline in the aminophylline group ( $p$ $<0.05$ ).

The values for arterial blood gases, HR, and BPs before and after treatment with aminophylline during normoxia and the changes during the control and pretreatment hypoxic trials are shown in Table 2. Treatment with aminophylline during normoxia produced a significant elevation in $\mathrm{PAO}_{2}$ and $\mathrm{HR}$, but had little effect on $\mathrm{PACO}_{2}, \mathrm{pH}$, or BPs. In the control trials, 6 min of hypoxia was associated with a decrease in blood pressure and $\mathrm{PACO}_{2}$ and an increase in $\mathrm{pH}$ and $\mathrm{HR}$. After pretreatment with

Table 1. Hypoxic breathing pattern

\begin{tabular}{lccc}
\hline \multicolumn{1}{c}{ \% of epochs } & Control & Aminophylline & $p$ \\
\hline Bolus & & & \\
$\quad$ Periodic & 16.7 & 20.1 & NS \\
Irregular & 85.7 & 25.0 & $<0.005$ \\
& & & \\
Pretreatment & & & \\
$\quad$ Periodic & 24.1 & 18.6 & NS \\
Irregular & 86.2 & 48.1 & $<0.005$ \\
\hline
\end{tabular}




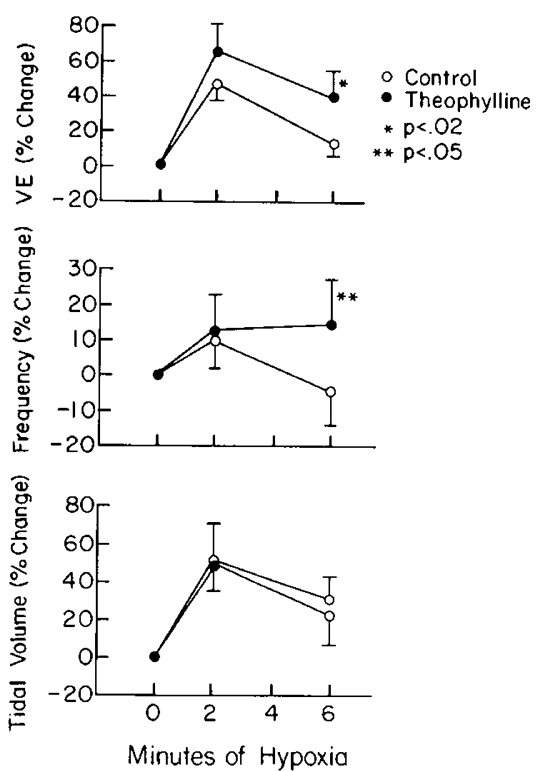

Fig. 1. Pretreatment experiments. Percentage changes in $V E$, $\mathrm{f}$, and $\mathrm{Vt}$ during hypoxia before (open circles) and after (closed circles) treatment with aminophylline. Changes from baseline (prehypoxia) are compared. Values are means \pm SEM.

Table 2. Pretreatment experiments (mean \pm SEM)

\begin{tabular}{lccc}
\hline & Normoxia & Hypoxia & Difference \\
\hline $\mathrm{PAO}_{2}$ & & & \\
Control & $54.8 \pm 2.3$ & $24.5 \pm 2.0$ & $30.4 \pm 3.3$ \\
Aminophylline & $65.7 \pm 4.3$ & $25.2 \pm 1.6$ & $40.1 \pm 5.9$ \\
$p$ & $<0.01$ & NS & $<0.05$
\end{tabular}

\begin{tabular}{lccc}
$\mathrm{PACO}_{2}$ & & & \\
$\mathrm{Con}$ trol & $31.6 \pm 1.8$ & $26.5 \pm 1.1$ & $5.2 \pm 1.3$ \\
Aminophylline & $29.6 \pm 1.9$ & $23.6 \pm 1.3$ & $5.9 \pm 1.2$ \\
$p$ & $\mathrm{NS}$ & $\mathrm{NS}$ & $\mathrm{NS}$ \\
$\mathrm{pH}$ & & & \\
$\quad$ Control & $7.44 \pm 0.02$ & $7.49 \pm 0.02$ & $0.01 \pm 0.01$ \\
Aminophylline & $7.48 \pm 0.02$ & $7.50 \pm 0.04$ & $0.01 \pm 0.03$ \\
$p$ & $\mathrm{NS}$ & $\mathrm{NS}$ & $\mathrm{NS}$ \\
& & & \\
$\mathrm{HR}$ & & & \\
Control & $140 \pm 8$ & $163 \pm 9$ & $22.9 \pm 5.6$ \\
Aminophylline & $157 \pm 8$ & $191 \pm 9$ & $32.3 \pm 4.5$ \\
$p$ & $<0.02$ & $<0.001$ & $\mathrm{NS}$ \\
& & & \\
$\mathrm{BPs}$ & & & \\
Control & $90 \pm 3$ & $73 \pm 4$ & $16.4 \pm 3.3$ \\
Aminophylline & $89 \pm 3$ & $78 \pm 4$ & $10.4 \pm 2.2$ \\
$p$ & $\mathrm{NS}$ & $<.25$ & $<0.05$ \\
\hline
\end{tabular}

aminophylline, hypoxia produced similar changes. When the changes in the control and pretreatment experiments were compared, $\mathrm{PAO}_{2}$ decreased more and BPs decreased less after pretreatment with aminophylline.

The effects of the bolus administration of aminophylline and saline during hypoxia on $\mathrm{Ve}, \mathrm{f}$, and $\mathrm{Vt}$ are shown in Figure 2. Prior to the administration of aminophylline or saline, both groups exhibited typical biphasic responses and by 6 min of hypoxia ventilation was not different from prehypoxia baseline values. Bolus administration of aminophylline was associated with a significant increase in Ve and $\mathrm{Vt}$ when compared to the changes associated with the placebo. Although $f$ increased after the administration of aminophylline, this change was not different from the increase associated with saline infusion.
The effect of aminophylline and saline, administered during hypoxia, on $\mathrm{PAO}_{2}, \mathrm{PACO}_{2}, \mathrm{pH}, \mathrm{BPs}$, and $\mathrm{HR}$ are illustrated in Table 3 . When compared to the infusion of saline, aminophylline did not significantly improve $\mathrm{PAO}_{2}$, but decreased $\mathrm{PACO}_{2}$ and
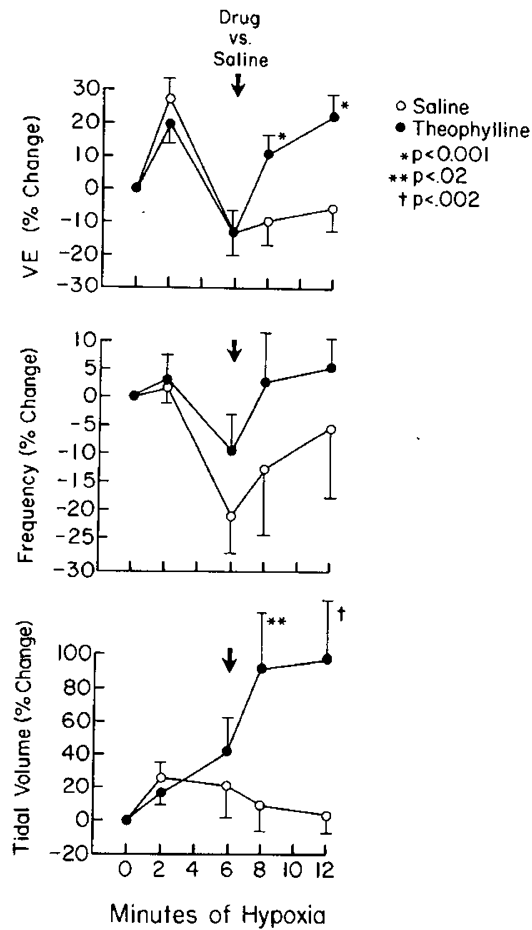

Fig. 2. Bolus experiments. Percentage changes in $V E$, $\mathrm{f}$, and $\mathrm{Vt}$ during hypoxia. After 6 min of hypoxia the animals were either treated with saline (open circles) or aminophylline (closed circles). Changes from 6 min of hypoxia are compared. Values are means \pm SEM.

Table 3. Bolus experiment (mean \pm SEM)

\begin{tabular}{|c|c|c|c|c|}
\hline & Normoxia & Hypoxia $^{1}$ & $\begin{array}{c}\text { Hypoxia }^{2} \\
+ \text { drug }\end{array}$ & $\begin{array}{c}\text { Difference } \\
(2-1)\end{array}$ \\
\hline \multicolumn{5}{|l|}{$\mathrm{PAO}_{2}$} \\
\hline Saline & $58.0 \pm 1.0$ & $20.2 \pm 0.7$ & $19.0 \pm 0.7$ & $1.2 \pm 0.4$ \\
\hline $\begin{array}{l}\text { Amino- } \\
\text { phylline }\end{array}$ & $56.6 \pm 3.6$ & $18.8 \pm 1.3$ & $19.8 \pm 1.2$ & $1.0 \pm 1.1$ \\
\hline$p$ & & & & NS \\
\hline \multicolumn{5}{|l|}{$\mathrm{PACO}_{2}$} \\
\hline Saline & $38.8 \pm 1.3$ & $36.3 \pm 1.4$ & $38.9 \pm 1.9$ & $2.6 \pm 0.9$ \\
\hline $\begin{array}{l}\text { Amino- } \\
\text { phylline }\end{array}$ & $36.3 \pm 1.7$ & $36.2 \pm 2.1$ & $34.8 \pm 2.1$ & $1.4 \pm 0.8$ \\
\hline$p$ & & & & $<0.01$ \\
\hline \multicolumn{5}{|l|}{$\mathrm{pH}$} \\
\hline Saline & $7.46 \pm 0.01$ & $7.49 \pm 0.01$ & $7.46 \pm 0.02$ & $0.03 \pm 0.01$ \\
\hline $\begin{array}{l}\text { Amino- } \\
\text { phylline }\end{array}$ & $7.47 \pm 0.02$ & $7.47 \pm 0.01$ & $7.48 \pm 0.01$ & $0.01 \pm 0.01$ \\
\hline$p$ & & & & $<0.02$ \\
\hline \multicolumn{5}{|l|}{ HR } \\
\hline Saline & $121 \pm 3$ & $135 \pm 3$ & $141 \pm 9$ & $6.0 \pm 2.9$ \\
\hline $\begin{array}{l}\text { Amino- } \\
\text { phylline }\end{array}$ & $121 \pm 5$ & $134 \pm 8$ & $159 \pm 11$ & $24.4 \pm 5.9$ \\
\hline$p$ & & & & $<0.02$ \\
\hline \multicolumn{5}{|l|}{ BPs } \\
\hline Saline & $79 \pm 4$ & $77 \pm 4$ & $77 \pm 4$ & $3.6 \pm 2.6$ \\
\hline $\begin{array}{l}\text { Amino- } \\
\text { phylline }\end{array}$ & $83 \pm 4$ & $80 \pm 5$ & $81 \pm 4$ & $3.0 \pm 4.7$ \\
\hline$p$ & & & & NS \\
\hline
\end{tabular}


increased $\mathrm{pH}$. The effect of aminophylline on BPs was not different than the effect of saline but HR increased more after aminophylline than after saline.

\section{DISCUSSION}

Our results confirm the reports of other investigators that the biphasic hypoxic ventilatory response is present in the spontaneously breathing newborn piglet (10). Our finding that during hypoxia, the increase and subsequent decrease in ventilation results from an increase followed by a decrease in both $\mathrm{Vt}$ and $\mathrm{f}$, is also consistent with the work of other investigators (14). Our results demonstrate that the decrease in ventilation associated with hypoxia can be reversed by the rapid administration of aminophylline and partially prevented by pretreatment with aminophylline.

The bolus administration of aminophylline during hypoxia resulted in a significant increase in $\mathrm{Vt}$ and Ve. Treatment with aminophylline during normoxia also resulted in a significantly elevated Vt. This is consistant with other reports showing that during normoxia, xanthines cause a large increase in $\mathrm{Vt}$ with a smaller increase in $f(22,23)$. Although the respiratory stimulatory effects of methylxanthines have been well documented, the primary sites of action and neurochemical mechanisms remain uncertain. Investigators have suggested that xanthines could stimulate respiration by affecting respiratory muscle contractility (24), pulmonary mechanics (7), metabolic rate (25), the release of catecholamines (26), medullary blood flow (27), or by directly increasing central respiratory activity (22).

In a series of sophisticated studies in adult cats, Eldridge $e t$ al. (22), using phrenic nerve activity as an indicator of central respiratory activity, determined that the primary stimulatory action of aminophylline is probably not mediated via pulmonary mechanical factors, vagal reflexes, changes in arterial $\mathbf{P A C O}_{2}$, release of substances from the adrenal, or changes in whole body metabolic rate. Aubier et al. (28) have demonstrated that aminophylline improves diaphragmatic contractility in adult volunteers, and renders it less susceptible to fatigue. These authors have also suggested that the increase in $\mathrm{Ve}$ and $\mathrm{Vt}$ associated with aminophylline infusion is primarily caused by improved diaphragmatic efficiency (24). These data suggest that the primary stimulatory effect of methylxanthines on respiration involves both a direct stimulation of central respiratory centers and an improvement of diaphragmatic contractility.

Pretreatment with aminophylline had no effect on the initial increase in $\mathrm{Vt}$ and $\mathrm{f}$ caused by hypoxia, but prevented the subsequent decrease in $f$ with little effect on Vt. A number of investigators have demonstrated that theophylline causes respiration to become more regular in infants with apnea of prematurity (23). In our model, pretreatment with theophylline regularized respiration during hypoxia. This suggests that the effect on respiratory frequency we observed may be secondary to the prevention of respiratory irregularity associated with hypoxia.

Our results disagree with those of Long and Lawson (29) who found that the pretreatment of neonatal piglets with aminophylline had no effect on phrenic nerve output during hypoxia. Although the reasons for the differences in our results are not clear, differences in the experimental models may be important. Although both studies were done with newborn piglets, our studies were carried out in fully intact, lightly anesthetized, spontaneously breathing animals, while the studies of Long and Lawson (29) were carried out in anesthetized, paralyzed, vagotomized animals, servo-ventilated to minimize changes in $\mathbf{P A C O}_{2}$. It is possible that differences in afferent input from central chemoreceptors and pulmonary receptors may have contributed to the differences in the results of the two studies. Another possibility is that our results reflect the effect of aminophylline on diaphragmatic fatigue during hypoxia. Aminophylline may have improved contractility resulting in a diminution in the decrease in $\mathrm{Ve}(28)$. Pretreatment with aminophylline, however, prevented a decrease in $\mathrm{f}$ with little effect on $\mathrm{Vt}$, suggesting a central, rather than a peripheral effect.

Our finding that pretreatment with aminophylline prevented the decrease in $f$ rather than Vt during hypoxia suggests that methylxanthines may also interfere with mechanisms responsible for hypoxic ventilatory depression. It is possible that the primary respiratory effect of methylxanthines may involve one set of mechanisms, while the effect on hypoxic respiratory depression may involve another. Aminophylline could affect several of the suggested mechanisms of hypoxic ventilatory depression including changes in metabolic rate, exhaustion of facilitory neurotransmitter stores, alterations in cerebral blood flow, and the release of adenosine.

Eldridge et al. (22) found that aminophylline increases phrenic nerve output in paralyzed adult cats without a concomitant increase in metabolic rate, while other investigators have reported increases in metabolic rate in spontaneously breathing human infants treated with aminophylline for apnea of prematurity (23). Eldridge et al. (22) suggested that the difference in these findings may be due to the neuromuscular blocade in their animals. In the unparalyzed animal, aminophylline may potentiate the contraction of skeletal muscle both by increasing tonic activity due to central neural mechanisms and by increasing muscle tension due to an effect on transmitters at the neuromuscular junction (30).

It is possible, therefore, that in spontaneously breathing animals, aminophylline may prevent a decrease in metabolic rate which may occur during hypoxia. Early reports of Cross $e t$ al. (9) demonstrated decreases in oxygen consumption during $15 \%$ oxygen breathing in human infants (1). Hill (31) demonstrated in newborn kittens, however, that the decrease in oxygen consumption does not occur during hypoxia when the animal is at thermoneutrality. In our studies, the skin temperature of all piglets was servo-controlled to maintain core temperatures between 38 and $39^{\circ} \mathrm{C}$. It is unlikely, that a temperature-related decrease in metabolism is responsible for the decrease in ventilation we observed.

Xanthines may affect respiration by altering blood flow. Lawson and Long (10) have suggested that during hypoxia a combination of a vasodilitation, increased cardiac output, local increases in brain perfusion, and an increase in $\mathrm{CO}_{2}$ carrying capacity may result in net $\mathrm{CO}_{2}$ removal and thus a removal of hydrogen ions from brain chemosensory tissues. The resultant inhibitory central chemosensor input may then override peripheral chemosensor excitatory input resulting in a net decrease in ventilation. Xanthines are potent cerebral vasoconstrictors (32, 33 ), and aminophylline may affect ventilation by interfering with changes in cerebral perfusion that occur during hypoxia.

Xanthines may reduce hypoxic ventilatory depression by facilitating the release of catecholamines from the adrenal $(26,34)$. Infused catecholamines have been reported to stimulate ventilation (35). The levels of xanthines, however, required to release catecholamines are generally greater than those usually used clinically or in our experiments (32). Also, Eldridge et al. (22) were unable to blunt the stimulatory effect of xanthines by ablating the adrenals and Bhat et al. (36) were unable to detect any increase in urinary catecholamine metabolites in infants treated with aminophylline for apnea of prematurity. These reports suggest that it is unlikely that the effects we observed were due to an increase in circulating catecholamines.

We propose that the effects of aminophylline that we observed may be due to the competitive inhibition of the actions of the nucleoside, adenosine. In animal models, adenosine is rapidly released during hypoxia (19), and most is deaminated to inosine and hypoxanthine. This is consistent with reports that inosine, hypoxanthine, and xanthine-adenosine metabolites, can be measured in the cerebral spinal fluid of asphyxiated human infants (37). The properties of rapid release and uptake make adenosine an ideal candidate as a regulator of cerebral blood flow (4) and as a modulator of synaptic transmission (38). Also, 
adenosine depresses the firing rate of cerebral neurons (39). It is possible, therefore, that during hypoxia, both central and vascular effects of adenosine could be involved in ventilatory depression.

In the newborn animal, the systemic administration of adenosine analogues causes physiologic changes similar to those found during severe, prolonged hypoxia, including bradycardia, hypotension, and apnea. Also, the direct application of adenosine analogues to the brainstem depresses ventilation $(17,20)$. An adenosine receptor inhibitor such as aminophylline would be expected to reverse these effects. In this study, pretreatment with aminophylline reduced the amount of hypoxic ventilatory depression and reduced the fall in BPs. Although HR did not fall during the brief exposure to hypoxia, the mean HR tended to be higher after pretreatment with aminophylline.

It has frequently been proposed that the stimulant effects of methylxanthines are secondary to an accumulation of cyclic AMP caused by an inhibition of nucleotide phosphodiesterase. Recent evidence, however, indicates that this may not be the major mechanism involved. Xanthines, even at maximal therapeutic levels, have been found to inhibit phosphodiesterase activity in many tissues by only 5 to $10 \%$ (40). Furthermore, methylxanthines in this concentration range have only rarely been observed to potentiate hormone-induced effects, even in those instances where other evidence exists for the involvement of cyclic AMP (32). Adenosine has also been shown to be a potent modulator of adenylate cyclase in many tissues. In the brain, adenosine appears to catalyze the production of cyclic AMP (13) while theophylline has been found to decrease levels of cyclic AMP (40). It is reasonable to postulate, therefore, that the effects of theophylline on Ve, HR, and BPs during hypoxia may be due to the inhibition of the actions of adenosine rather the phosphodiesterase.

In conclusion, our results have shown that in the newborn piglet, the rapid infusion of aminophylline during hypoxia increases $\mathrm{Vt}$ and reverses ventilatory depression. Also, pretreatment with theophylline at low levels $(<15 \mu \mathrm{g} / \mathrm{ml})$ modifies the biphasic hypoxic ventilatory response, reducing the degree of ventilatory depression, primarily through a maintenance of respiratory frequency. We suggest that the effect of aminophylline on respiration during hypoxia may be the result of actions at more than one site and that the resultant respiratory pattern is a balance between excitatory and inhibitory inputs. Our results are consistent with the hypothesis that the effects of pretreatment with aminophylline on the hypoxic ventilatory response may be due to its inhibitory actions on adenosine receptors and speculate that adenosine may play a role in respiratory control.

Acknowledgments. The author thanks Larry Suddarth, Linda Tuttle, and Brooks Koff for their help in performing the studies and John Kattwinkel for reviewing the manuscript.

\section{REFERENCES}

1. Cotton EK, Grunstein MM 1980 Effects of hypoxia on respiratory control in neonates at high altitude. J Appl Physiology 48:287-595

2. Rigatto H, Brady JP 1972 Periodic breathing and apnea in preterm infants I. Evidence for hypoventilation possibly due to central respiratory depression. Pediatrics 50:202-217

3. Rigatto H, Brady JP 1972 Periodic breathing and apnea in preterm infants. II. Hypoxia as a primary event. Pediatrics 50:219-228

4. Biscoe TJ, Purves MJ 1967 Carotid body chemoreceptor activity in the newborn lamb. J Physiol (Lond) 190:443-454

5. Blanco C, Hanson M, Johnson P, Rigatto H 1984 The pattern of breathing of kittens during hypoxia. J Appl Physiol 56:12-17

6. Schweiler GH 1968 Respiratory regulation during postnatal development in cats and rabbits and some of its morphological substrate. Acta Physiol Scand Suppl 304:49-63

7. LaFramboise WA, Guthrie RD, Standaert TA, Woodrum DE 1983 Pulmonary mechanics during the ventilatory response to hypoxia in the newborn monkey. J Appl Physiol 55:1008-1014

8. Jansen AH, Chernick V 1983 Development of respiratory control. Physiol Rey 63:437-483
9. Cross KW, Tizard JPM, Trythall DAH 1958 The gaseous metabolism of the newborn infant breathing 15\% oxygen. Acta Paediatr Scand 47:217-237

10. Lawson EE, Long WA 1983 Central origin of biphasic breathing pattern during hypoxia in newborns. J Appl Physiol 55:483-488

11. Agarwal HC, Glisson SN, Himwich WA 1966 Changes in monoamines of rat brain during postnatal ontogeny. Biochem Biophys Acta 130:511

12. Coyle JT 1976 Neurochemical aspects of the development of the dopaminergic innervation of the striatum. In: Brazer M, Coceani F (eds) Brain Dysfunction in Infantile Febrile Convulsions. Raven Press, New York, pp 25-39

13. Smellie FW, Davis CW, Daly JW, Wells JN 1979 Alkylxanthines: inhibition of adenosine-elicited accumulation of cyclic AMP in brain slices and of brain phosphodiesterase activity. Life Sci $24: 2475-2482$

14. Grunstein MM, Hazinski TA, Schleuter MA 1918 Respiratory control during hypoxia in newborn rabbits: implied action of endorphins. J Appl Physiol 51:122-130

15. Hedner J, Hedner T, Bergman B, Lundberg D 1980 Respiratory depression by GABA-ergic drugs in the preterm rabbit. J Dev Physiol 2:401-407

16. Darnall RA 1982 Theophylline reduces ventilatory depression in hypoxic newborn piglets. Pediatr Res 16:347A(abstr)

17. Kattwinkel J, Darnall RA 1982 Adenosine: a possible mediator of neonatal apnea. Pediatr Res 16:352A(abstr)

18. Aranda JV, Turmen TL 1979 Methylxanthines in apnea of prematurity. Clin Perinatol 6:87-108

19. Winn HR, Rubio R, Berne RM 1981 Brain adenosine concentration during hypoxia in the rat. Am J Physiol 241:H235-H242

20. Lagercrantz H, Yamamoto $Y$, Fredholm BB, Prabhakar NR, Von Euler $C$ 1984 Adenosine analogues depress ventilation in rabbit neonates. Theophylline stimulation of respiration via adenosine receptors? Pediatr Res $18: 387-390$

21. Bonferroni CE 1936 II Calcalo delle assicurazioni su gruppi di teste. In Studii in onore del Prof. S. O. Carboni, Roma

22. Eldridge FL, Millhorn DE, Waltrop TG, Kiley JP 1983 Mechanisms of respiratory effects of methylxanthines. Respir Physiol 53:239-261

23. Gerhardt T, McCarthy J, Bancalari E 1979 Effect of aminophylline on respiratory center activity and metabolic rate in premature infants with idiopathic apnea. Pediatrics 63:537-542

24. Aubier M, Murciano D, Viires N, Lecocquic Y, Palacios S, Pariente R 1983 Increased ventilation caused by improved diaphragmatic efficiency during aminophylline infusion. Am Rev Respir Dis 127:148-154

25. Cross KW, Oppe JE 1952 The effect of inhalation of high and low concentrations of oxygen on the respiration of premature infants. J Physiol (Lond) $117: 38$

26. Poisner AM 1973 Direct stimulant effect of aminophylline on catecholamine release from the adrenal medulla. Chem Pharmacol 22:469-476

27. Moyer JH, Miller SI, Tashnek AB, Bowman R, Smith CP 1952 The effect of theophylline with ethylenediamine (aminophylline) on cerebral hemodynamics in the presence of heart failure with and without Cheyne-Stokes respiration. J Clin Invest 31:267-272

28. Aubier M, De Troyer A, Sampson M, Macklem PT, Roussos C 1981 Aminophylline improves diaphragmatic contractility, N Engl J Med 305:249-252

29. Long WA, Lawson EE 1983 Neurotransmitters and biphasic respiratory response to hypoxia. J Appl Physiol 55:483-488

30. Breckenridge B, Burn JH, Matschinsky FM 1962 Theophylline, epinephrine, and neostigmine facilitation of neuromuscular transmission. Proc Natl Acad Sci USA 57:1893-1897

31. Hill JR 1959 The oxygen consumption of newborn and adult mammals: its dependence on the oxygen tension in the inspired air and on the environmental temperature. J Physiol (Lond) 149:346-373

32. Rall TW 1980 The xanthines. In: Gilman AG, Goodman LS, Gilman A (eds) The Pharmacological Basis of Therapeutics. MacMillan, New York, pp 592607

33. Berne RM, Winn HR, Rubio R 1981 The local regulation of cerebral blood flow. Progr Cardiovasc Dis 24:243-260

34. Berkowitz BA, Spector S 1971 Effect of caffeine and theophylline on peripheral catecholamines. Eur J Pharmacol 13:193-196

35. Cunningham DJC, Hey EN, Patrick JM, Lloyd BB 1963 The effect of noradrenaline infusion on the relation between pulmonary ventilation and the alveolar $\mathrm{pO}_{2}$ and $\mathrm{pCO}_{2}$ in man. Ann NY Acad Sci 109:756-771

36. Bhat AM, Scanlon JW, Lavenstein B, Chuang L, Karoum F 1983 Effect of theophylline on neurotransmitters in preterm infants with apnea. Clin Neuropharmacol 6:71-74

37. Meberg A, Saugstad OD 1978 Hypoxanthine in cerebrospinal fluid in children Scand. J Clin Lab Invest 38:437-440

38. Mcllwain H 1980 Adenosine in neurohumoral and regulatory roles in the brain. In: Genazzani E, Herken H (eds) Central Nervous System Studies in Metabolic Regulation and Function. Springer-Verlag, New York, pp 3-11

39. Phyllis JW, Kostopoulos GK, Limacher JJ 1975 A potent depressant action of adenine derivatives on cerebral cortical neurons. Eur J Pharmacol 30:125129

40. Beavo JA, Rogers NL, Crofford OB, Hardman JG, Sutherland EW, Newman EV 1970 Effects of xanthine derivatives on lipolysis and on adenosine $3^{\prime}, 5^{\prime}$ monophosphate phosphodiesterase activity. Mol Pharmacol 6:597-603

41. Daly JO 1977 Cyclic Nucleotides in the Central Nervous System. Plenum Press, New York 